\title{
Verificação da qualidade microbiológica em produtos alimentícios produzidos pela agricultura familiar em municípios integrantes do Território de Identidade Portal do Sertão
}

\author{
Maria Eduarda Matos Pereira ${ }^{1}$, Marília Lordêlo Cardoso Silva ${ }^{2}$, Elisa Teshima ${ }^{3}$, \\ Patrícia Teixeira Damasceno Lobo ${ }^{4}$ \\ 1. Bolsista FAPESB/UEFS, Graduanda em Engenharia de Alimentos, Universidade Estadual de Feira de Santana, e-mail: \\ eduardamatos98098@gmail.com \\ 2. Orientadora, Departamento de Tecnologia, Universidade Estadual de Engenharia de Alimentos, e-mail: \\ lilaengal@yahoo.com.br \\ 3. Professora, Departamento de Tecnologia, Universidade Estadual de Feira de Santana, e-mail: eteshima@gmail.com \\ 4. Técnica, Universidade Estadual de feira de Santana, e-mail: tricialobofs@yahoo.com.br
}

PALAVRAS CHAVE: Agricultura familiar, qualidade microbiológica, segurança alimentar.

\section{INTRODUÇÃO}

O território denominado Identidade Portal do Sertão é formado por 17 dos 417 municípios do estado baiano, sendo eles: Água Fria, Amélia Rodrigues, Anguera, Antônio Cardoso, Conceição da Feira, Conceição do Jacuípe, Coração de Maria, Feira de Santana, Ipecaetá, Irará, Santa Bárbara, Santanópolis, Santo Estêvão, São Gonçalo dos Campos, Tanquinho, Teodoro Sampaio e Terra Nova. Nestes municípios, aproximadamente 117.511 pessoas $(13,5 \%)$ estão ocupada com as atividades agrícolas, que se constitui como principal atividade para a maior parte da população rural dos municípios do Portal do Sertão (IBGE, 2010).

A agricultura familiar ocupa um espaço de $83 \%$ da agricultura da Bahia e o Portal do Sertão destaca-se pela produção de mandioca, o milho e o feijão e para as culturas permanentes de origem nativa, o caju, a pinha e o umbu. A pecuária é outra atividade presente no Portal do Sertão, com destaque para a bovinocultura, como também a ovinocultura e a caprinocultura (PTDRSS, 2012 apud BAHIA, 2017).

Apesar disto, a agricultura familiar baiana sobrevive em condições precárias, com pouca capacidade de se inserir no mercado devido baixa produtividade e dificuldade de incorporação de tecnologias, mantendo-se como público alvo de políticas sociais (BAHIA, 2016).

A maior dificuldade desses produtores está em regulamentar os seus produtos com bases na legislação de padrão microbiológico e de identidade e qualidade, devido a carência de laboratórios, para assim se inserirem no mercado formal de produtos alimentícios.

O presente trabalho está inserido num projeto em parceria com a Superintendência do Desenvolvimento do Nordeste (SUDENE), que tendo em vista o potencial de crescimento da agroindústria familiar da Bahia, propôs realizar análises microbiológicas de alimentos elaborados por diferentes produtores para verificar o atendimento aos padrões da legislação vigente, bem a necessidade de assistência técnica e capacitação do produtor rural para obter a qualificação dos seus produtos.

\section{MATERIAIS E MÉTODOS}

Treinamento em análise microbiológica

Inicialmente, foi realizado um treinamento em análises microbiológicas, que inclui preparação de meios de cultura, esterilização de vidrarias e aplicação de métodos analíticos para os detecção e contagem de micro-organismos usados como padrão de qualidade dos 
alimentos. O objetivo era aprimorar as habilidades para que as análises dos produtores tivessem o mínimo de erros possíveis por imperícia da equipe responsável pelas análises.

Durante o treinamento, os procedimentos foram cuidadosamente registrados para posterior criação de Procedimento Operacional Padrão para cada método executado, onde todas as etapas foram descritas com o objetivo de auxiliar o analista quando da realização das análises.

Análise microbiológica de produtos de origem animal

As amostras analisadas foram fornecidas por um produtor de iogurte, manteiga e requeijão da região do Portal do Sertão, que foram transportadas ao laboratório com embalagem primária devidamente lacrada em uma caixa de isopor com gelo. Foram analisados padrões microbiológicos dos produtos conforme os requisitos de seus respectivos Regulamento Técnico de Identidade e Qualidade. Para a manteiga e o queijo foram realizadas as análises de Coliformes totais (Coliformes a $35^{\circ} \mathrm{C}$ )/g, Coliformes Termotolerantes (Coliformes a $45^{\circ} \mathrm{C}$ )/g, Staphylococcus coagulase Positiva e Salmonella spp.. E para o Iogurte, as análises de bactérias láticas, coliformes totais, coliformes a $45^{\circ} \mathrm{C}$. A metodologia utilizada para análise de Salmonella spp. foi o Método BAM/FDA (2007) seguindo a descrição de Silva et al. (2010). A análise de coliformes totais e de coliformes a $45^{\circ} \mathrm{C}$ seguiu o método do número mais provável (NMP), a análise de Staphylococcus coagulase positiva e bactérias láticas seguiu o método de contagem direta em placas, metodologias da American Public Health Association (APHA)(2015), descritas por Silva et al. (2010).

Os resultados obtidos foram comparados com os critérios do Regulamento Técnico de Identidade e Qualidade específico de cada produto alimentício definidos pelo do Ministério da Agricultura, Pecuária e Abastecimento (MAPA), conferindo se estava de acordo ou não com os padrões microbiológicos de referência da legislação e foi elaborado um laudo para emissão ao consórcio.

\section{RESULTADOS E DICUSSÃO}

O treinamento sobre as análises microbiológicas, preparo e esterilização de vidrarias e a elaboração do Manual de Procedimentos Operacionais Padrão permitiram minimizar erros e garantir maior assertividade na execução das análises microbiológicas. Este Manual de Procedimentos Operacionais Padrão pode, inclusive, ser usado posteriormente por futuros pesquisadores para facilitar as suas análises.

\section{Análise do Iogurte}

O iogurte, como todos os produtos de origem animal, deve ter carga de microrganismos controlada para não causar danos ao alimento ou à saúde pública. As análises microbiológicas realizadas foram para bactérias láticas, coliformes totais, coliformes a $45^{\circ} \mathrm{C}$ conforme consta na Tabela 1.

Tabela 1 - Contagens obtidas nas análises microbiológicas da amostra de Iogurte produzido no território de identidade Portal do Sertão da Bahia, novembro de 2019

\begin{tabular}{llll}
\hline & \multicolumn{3}{l}{ Análises Microbiológicas (UFC/g)* do Iogurte } \\
\cline { 2 - 4 } Microrganismo & $\begin{array}{l}\text { Coliformes } \\
\text { Totais }\end{array}$ & $\begin{array}{l}\text { Coliformes } \\
\text { termotolerantes }\end{array}$ & $\begin{array}{l}\text { Bactérias } \\
\text { láticas }\end{array}$ \\
\hline Amostra & $1,1 \times 10^{3}$ & $<3$ & $1,1 \times 10^{8}$ \\
\hline Valor de referência** & 10 & 3 & $>10^{7}$ \\
* Valores expressos em Unidades Formadoras de Colônias por gramas (UFC/ $\mathrm{mL}) ; * *$ Instrução Normativa N & \\
46/2007 (BRASIL, 2007). \\
Fonte: A autora.
\end{tabular}


A contagem de Coliformes Totais do iogurte do presente estudo foi de $1,1 \times 10^{3}$ $\mathrm{NMP} / \mathrm{g}$, portanto, em desacordo com os critérios estabelecidos pela Normativa vigente (máximo de $10 \mathrm{NMP} / \mathrm{g}$ ) (BRASIL, 2007). O resultado para coliformes muito acima da legislação é indicativo de uma má higiene no processamento do Iogurte, principalmente os termotolerantes, que indicam uma contaminação fecal. A ausência de coliformes em Iogurtes e bebidas lácteas tem sido um resultado comum para muitos autores (OLIVEIRA; LYRA; ESTEVES, 2013).

Quanto a contagem de coliformes termotolerantes (coliformes a $45^{\circ} \mathrm{C}$ ), os resultados obtidos demonstraram que a amostra analisada está de acordo com os critérios estabelecidos pela Norma Vigente com uma contagem inferior a 3 NMP/g (BRASIL, 2007; BRASIL, 2001).

A amostra do iogurte apresentou contagem de bactérias lácticas de $1,1 \times 10^{8} \mathrm{UFC} / \mathrm{g}$, ou seja, dentro dos limites mínimos recomendados pela Instrução Normativa $N^{\circ}$ 46/2007, que tem como requisito que os microrganismos dos cultivos utilizados devem ser viáveis e ativos e estar em concentração igual ou superior a $10^{7} \mathrm{UFC} / \mathrm{g}$ no produto final e durante seu prazo de validade. Um número muito baixo de bactérias láticas no iogurte poderia indicar, por exemplo, falha no processamento (FRANCO; LANDGRAF, 2008 apud BERTICELLI; MOTTA, 2011).

Tais resultados para o Iogurte nos leva a considerar uma melhoria nos padrões de higiene da produção e treinamento de colaboradores para a diminuir os níveis de coliformes totais (coliformes a $35^{\circ} \mathrm{C}$ ) e para evitar posteriormente contaminações que possam prejudicar a qualidade dos produtos.

Análise do requeijão

Foram realizadas as análises de coliformes a $45^{\circ} \mathrm{C}$ e a $35^{\circ} \mathrm{C}$, Staphylococcus aureus e Salmonella sp., conforme a Tabela 2.

Tabela 2 - Contagens obtidas nas análises microbiológicas da amostra de requeijão produzido no território de identidade Portal do Sertão da Bahia, novembro de 2019.

\begin{tabular}{lllll}
\hline & \multicolumn{4}{l}{ Análises Microbiológicas (UFC/g)* do requeijão } \\
\cline { 2 - 5 } Microrganismo & $\begin{array}{l}\text { Coliformes } \\
\text { Totais }\end{array}$ & $\begin{array}{l}\text { Coliformes } \\
\text { termotolerantes }\end{array}$ & $\begin{array}{l}\text { Staphylococcus } \\
\text { coagulase positiva }\end{array}$ & Salmonella \\
\hline Amostra & 3,6 & $<3$ & 0 & Aus \\
\hline Valor de referência** & 100 & 10 & 1000 & $A u s$ \\
\hline Valores expressos em Unidades Formadoras de Colônias por gramas (UFC/ g); **Portaria MAPA n ${ }^{\circ} 359 / 1997$ \\
(BRASIL, 1997).
\end{tabular}

A contagem de coliformes totais para a amostra de requeijão foi de $3,6 \mathrm{NMP} / \mathrm{g}$, estando de acordo com a legislação vigente, cujo critério de aceitação para Coliformes Totais (Coliformes a $35^{\circ} \mathrm{C}$ )/g é no máximo $100 \mathrm{NMP} / \mathrm{g}$. Quanto a análise de coliformes termotolerantes, a contagem foi inferior a 3,0 NMP/g portanto, em acordo com a Normativa vigente, que impõe como critérios número máximo de coliformes termotolerantes de 10 NMP/g (BRASIL, 1997).

A contagem em placas para Staphylococcus foi de 1,0x10 $\mathrm{UFC} / \mathrm{g}$, em que 5 colônias foram submetidas a análise de produção de coagulase, e foi considerado negativo para todas elas. Cepas de Staphylococcus coagulase fortemente positivas são consideradas Staphylococcus aureus (SILVA et al., 2010), e a legislação apenas referencia como critério de qualidade microbiológica as cepas de Staphylococcus coagulase positiva (no máximo $1 \times 10^{3} \mathrm{UFC} / \mathrm{g}$ ). Dessa forma, o requeijão encontra-se dentro dos padrões exigidos pela legislação em vigor (BRASIL, 1997). 
A presença de Staphylococcus coagulase positiva além de ser um importante indicador das condições higiênico-sanitárias da sua produção e conservação, pode ser causador de intoxicação estafilocócica, devido à ingestão de alimentos contaminados com enterotoxinas termoestáveis produzidas, principalmente, por S. aureus (RESTA; OLIVEIRA, 2013). Segundo Sena (2000) apud Silva et al. (2011) estes microrganismos são capazes de produzir toxinas independentemente de serem coagulase positiva ou não, e a presença destas enterotoxinas estafilocócicas no leite e nos produtos lácteos tem sido constatada em diversos estudos. No entanto, a legislação apenas faz referência a quantidade de Staphylococcus coagulase positiva permitida no alimento.

A amostra de requeijão do produtor apresentou ainda ausência de Salmonella, em conformidade com a Legislação vigente do país. A Salmonella é um dos microrganismos mais vigiados pela legislação devido ao seu alto grau de patogenicidade. Ela é responsável por muitos surtos alimentares de gastroenterites podendo causar desde uma diarreia até o óbito do indivíduo, sendo encontrada, em geral, em alimentos de origem animal, como carnes, ovos, leite e outros (MADALOSSO et al., 2008).

Silva et al. (2011) avaliaram em seu trabalho as condições higiênico-sanitárias de amostras qualidade microbiológica de requeijão produzido em Tocantins - MG e obteve resultados semelhantes para coliformes totais e termotolerantes, entretanto, apresentou Staphylococcus coagulase positiva em todas as suas análises, ainda que dentro do permitido pela legislação.

Dessa forma o requeijão cumpriu todos os todos os requisitos microbiológicos, estando apto para inserir o seu produto no mercado formal.

Análise da manteiga

A amostra de manteiga do produtor foi submetida a análise de coliforme totais, coliformes termotolerantes, Staphylococcus e Salmonella spp., conforme consta na Tabela 3.

Tabela 3 - Contagens obtidas nas análises microbiológicas da amostra de manteiga produzida no território de identidade Portal do Sertão da Bahia, novembro de 2019.

\begin{tabular}{lllll}
\hline & \multicolumn{4}{l}{ Análises Microbiológicas (UFC/g)* da manteiga } \\
\cline { 2 - 5 } Microrganismo & $\begin{array}{l}\text { Coliformes } \\
\text { Totais }\end{array}$ & $\begin{array}{l}\text { Coliformes } \\
\text { termotolerantes }\end{array}$ & $\begin{array}{l}\text { Staphylococcus } \\
\text { coagulase positiva }\end{array}$ & Salmonella \\
\hline Amostra & $>1100$ & $<3$ & 0 & Aus \\
\hline Valor de referência** & 100 & 10 & 100 & Aus \\
Valores expressos em Unidades Formadoras de Colônias por gramas (UFC/g); ** Portaria n ${ }^{\circ}$ & $146 / 1996$ \\
(BRASIL, 1996). & & & \\
Fonte: A autora.
\end{tabular}

Para a análise de coliformes totais, a manteiga apresentou contagem superior a 1.100 $\mathrm{NMP} / \mathrm{g}$, sendo um valor muito alto comparado aos valores legais da legislação (máximo de $100 \mathrm{NMP} / \mathrm{g}$ ). Por outro lado, a contagem de coliformes termotolerantes manteve-se dentro do permitido pela legislação é $10 \mathrm{NMP} / \mathrm{g}$ (BRASIL, 1996; BRASIL, 2001).

Contagem semelhante de coliformes totais foi encontrado por Berticelli e Motta (2011) para a análise de uma marca de manteiga, com valor mais de dez vezes maior do que o limite permitido, indicando que possivelmente não foi fabricado em boas condições de higiene durante a linha de processamento, na manipulação ou ocorreram falhas no processo que causaram a contaminação do mesmo.

A análise de Staphylococcus teve como resultado negativo para o teste de coagulase. A legislação apenas faz referência a quantidade de Staphylococcus coagulase positiva (BRASIL, 1996; BRASIL, 2001).

Os testes para presença de Salmonella spp. foram todos negativos, estando o produto em conformidade com a legislação (BRASIL, 1996; BRASIL, 2001). 
Desta forma, a manteiga se encontra dentro da conformidade para a maioria dos microrganismos, exceto para coliformes totais. Isto é um forte indicativo de más condições higiênicas, contaminação pós-processamento, limpeza e sanitização deficientes, tratamentos térmicos ineficientes ou manipulação durante o processamento ou estocagem (CARDOSO, 2000).

De acordo com os resultados das análises, recomenda-se uma assistência técnica a este produtor quanto a higiene no processamento da manteiga ou nos cuidados necessários pósprocessamento, visando uma redução na contagem de coliformes totais.

\section{CONSIDERAÇÕES FINAIS}

A amostra de requeijão do produtor estava de acordo com os padrões vigentes, no entanto, o iogurte e a manteiga apresentaram elevada contagem de coliformes totais.

A contaminação por coliformes totais $\left(35^{\circ} \mathrm{C}\right)$ foi $\mathrm{o}$ principal parâmetro microbiológico em desacordo com os padrões vigentes, indicando deficiências na produção, que podem estar associadas a uma má higiene no maquinário do processo produtivo assim como aos maus hábitos de higiene dos manipuladores ou a contaminação pósprocessamento, existindo, portanto, uma necessidade de uma assistência técnica a este produtor e um treinamento aos seus colaboradores, visando garantir a qualidade do produto final e consequentemente redução na contagem de coliformes totais.

\section{REFERÊNCIAS BIBLIOGRÁFICAS}

BAHIA. Secretaria do Planejamento (SEPLAN). Cenários Prospectivos para a BAHIA 2015-2030. Salvador, 2016.2 Disponível em:<http://www.seplan.ba.gov.br/arquivos/File/publicacoes/outros/Cenarios_Online.pdf.

Acesso em: 02 jun. 2020.

BAHIA. Secretaria do Planejamento (SEPLAN). Plano Territorial de Desenvolvimento Rural Sustentável e Solidário do Portal do Sertão, Feira de Santana - BA, CODETER Portal do Sertão, UFRB, CNPq, MDA, 2017. Disponível em $<$ http://www.seplan.ba.gov.br/arquivos/File/politicaterritorial/PUBLICACOES_TERRITORIAIS/Planos-Territoriais-de-DesenvolvimentoSustentavel-PTDS/PTDS_do_Portal_do_Sertao.pdf. . Acesso em: 03 jun. 2020.

BERTICELLI, D; MOTTA, E. Caracterização físico-química e microbiológica de manteigas comercializadas em Francisco Beltrão - PR. Trabalho de Conclusão de Curso Universidade Tecnológica Federal do Paraná - UTFPR. Francisco Beltrão. 2011. Disponível em: http://repositorio.roca.utfpr.edu.br/jspui/bitstream/1/259/1/FB_COALM_2011_2_04.pdf. Acesso em: 18 jul. 2020.

BRASIL. Ministério da Agricultura, Pecuária e do Abastecimento. Instrução normativa $\mathrm{n}^{\circ} 46$, de 23 de outubro de 2007. Aprova o Regulamento Técnico de Identidade e Qualidade de Leites Fermentados. Brasília - DF, 2007.

BRASIL, Ministério da Agricultura e do Abastecimento. Portaria no 359 de 04 de setembro de 1997. Aprova o Regulamento técnico para fixação de identidade e qualidade do requeijão cremoso ou requesón. Brasília - DF, 1997. 
BRASIL. Ministério da Agricultura, Pecuária e do Abastecimento. Portaria ${ }^{\circ} 146$, de 07 de março de 1996. Aprova Regulamento Técnico de Identidade e Qualidade dos Produtos Lácteos. Brasília - DF, 1996.

BRASIL. Ministério da Saúde. Agência Nacional de Vigilância Sanitária. Resolução RDC nº 12, de 02 de janeiro de 2001. Aprova o Regulamento sobre padrões microbiológicos para alimentos e seus Anexos I e II. Brasília - DF, 2001.

CARDOSO, A.L.S.P. et al. Pesquisa de Salmonella spp., coliformes totais, coliformes fecais e mesófilos em carcaças e produtos derivados de frango. Arquivos do Instituto Biológico, São Paulo, v. 67, ed. 1. out. 2000. ISSN 1806-423-X. Disponível em: http://www.biologico.sp.gov.br/uploads/docs/arq/V67_1/pesquisa_salmonella.htm. Acesso em: 14 jul. 2020.

IBGE. Instituto Brasileiro de Geografia e Estatística. Censo Populacional, 2010. Disponível em:Acessado em: https://censo2010.ibge.gov.br/sinopse/index.php?dados=21\&uf=29. 3 jun. 2020.

MADALOSSO, G. et al. Surto alimentar por Salmonella entérica sorotipo Enteritidis em restaurante, São Paulo, SP - dezembro de 2006. Boletim Epidemiológico Paulista, São Paulo, v. 5, ed. 55, p. 5-11, jul. 2008. ISSN 1806-423-X. Disponível em:http://periodicos.ses.sp.bvs.br/pdf/bepa/v5n55/v5n55a02.pdf. Acesso em: 9 jul. 2020.

OLIVEIRA, F. M. de; LYRA, I. N.; ESTEVES, G. S. G. Avaliação microbiológica e físicoquímica de iogurtes de morango industrializados e comercializados no município de Linhares - ES. Revista Brasileira de Produtos Agroindustriais, Campinas, v. 15, ed. 2, p. 147-155, 2013. DOI ISSN: 1517-8595. Disponível em: http://www.deag.ufcg.edu.br/rbpa/rev152/Art1526.pdf. Acesso em: 9 jul. 2020.

RESTA, M. S. A.; OLIVEIRA, T. C. R. M. de. Avaliação do padrão estafilococos coagulase positiva estabelecido pela legislação brasileira para massas alimentícias. Brazilian journal of Food Technology, Campinas, v. 16, ed. 4, p. 319-325, out./Dez. 2013. DOI http://dx.doi.org/10.1590/S1981-67232013005000038

Disponível em:https://www.scielo.br/pdf/bjft/v16n4/a09v16n4.pdf. Acesso em: 9 jul. 2020.

SILVA, C. R. da; BARBOSA, J. B.; FIRMINO, F. C.; CALDONCELLI, L. L. Qualidade microbiológica de requeijão e doce de leite pastoso produzidos em Tocantins - MG. Revista Perspectivas Online. Tocantins, v. 1, ed. 1, 2011. Disponível em: https://ojs3.perspectivasonline.com.br/biologicas_e_saude/article/download/516/428/. Acesso em: 16 jul. 2020.

SILVA, N. da J. et al. Manual de Métodos de Análise Microbiológica de Alimentos e Água. $4^{\circ}$ edição. São Paulo: VARELA, 2010.

\section{AGRADECIMENTOS}

A FAPESB pelo financiamento do Projeto "Verificação da qualidade microbiológica em produtos alimentícios produzidos pela agricultura familiar em municípios integrantes do Território de Identidade Portal do Sertão" e a UEFS pela concessão da Bolsa de Iniciação Científica. 